a Patient Safety course, details of which can be found on the Board's Web site.

Diplomates may apply for MOC in the year their certificate expires or, if they wish to do so, they may apply up to two years before it expires. However, the new certificate will be dated 10 years from the date of expiration of their original certificate or most recent MOC certificate. In other words, going through the MOC process early does not alter the 10-year validation. Diplomates certified prior to 1976 (the year that time-limited certificates were initiated) are also required to participate in MOC if they wish to maintain valid certificates.

Information outlining the rules, requirements, and application deadline for the 10-year Milestone of MOC in thoracic surgery is available on the Board's Web site at www.abts.org. For additional information, please contact the American Board of Thoracic Surgery, 633 N Saint Clair St, Ste 2320, Chicago, IL 60611; telephone (312) 202-5900; E-mail: moc@abts.org.

\section{Cardiac Surgery Intersociety Alliance}

\section{Call for Proposals to Be a Pilot Site for CSIA Supported Programs}

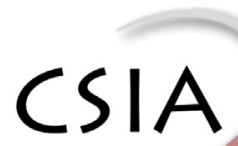

CARDIAC SURGERY INTERSOCIETY ALLIANCE

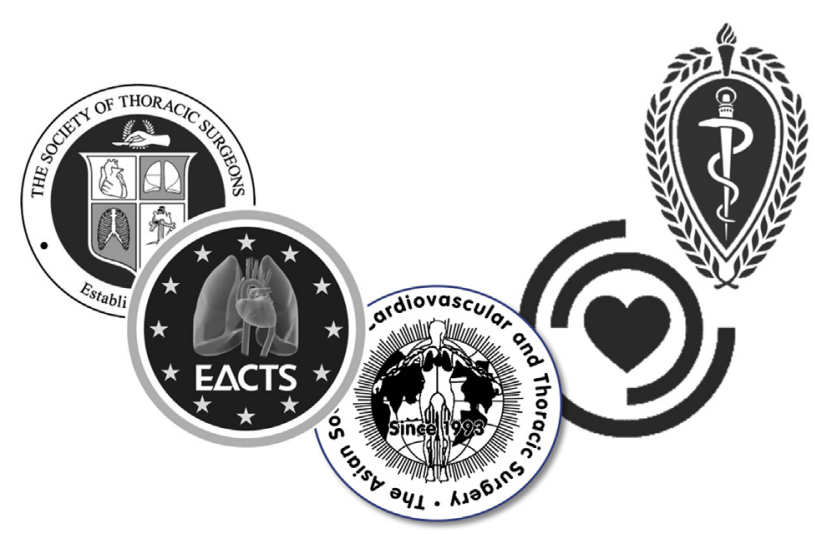

The American Association for Thoracic Surgery, the European Association for Cardio-Thoracic Surgery, the Asian Society for Cardiovascular and Thoracic Surgery, the Society of Thoracic Surgeons, and the World Heart Federation jointly oversee an alliance that was charged with evaluating, endorsing, and working with potential sites in low-income countries to increase access to sustainable cardiac surgery with particular emphasis on rheumatic heart disease.

Cardiac Surgery Intersociety Alliance (CSIA) will initially select 3 pilot sites: 1 in West Africa; 1 in Southern/East
Africa; and 1 in Asia, where local cardiac surgery, independent from fly-in missions, has been established but resource constraints severely limit the surgical capacity. CSIA sees itself as a facilitator of a site-specific partnership soliciting donor support as well as staff training with the goal of increasing the delivery of cardiac surgery on the basis of local capacity. CSIA will also facilitate the establishment of a collaborative research partnership with a tertiary institution of a high-income country. Central to such initiatives is a strongly motivated initiator/champion that can be a health professional, a health manager, an institution, or a government.

Once local consensus has been obtained, proposals need to include a clear analysis and projection of need supported by the following documents.

1. A "project development plan" that lays out the financial and organizational details of the current cardiac surgical capacity as well as proposed growth curve over the next 5 years (eg, 50-200 cases annually) with clear distinction between existing local commitments and the gap that is sought to be closed by involving CSIA members and institutions.

2. Clear current staff establishment, showing the limits of capacity of the existing team and the needs arising from growth, highlighting the time plan when training needs to commence of further doctors/nurses/ perfusionists, and, again, the local contribution to these needs versus the gap requested to be closed with CSIA assistance.

3. A strong letter of intent by the local "initiator" explaining why he/she thinks that the site should qualify for CSIA support, and a statement that he/ she will be the person(s)/organization interacting with the CSIA and driving the process on the ground with passion and commitment.

4. Written commitment by a local authority (local government or city council, ministry of health, etc) that they support the program within the envisaged scope and guarantee their part for sustainability, including specific portions of the program for which they will guarantee support. 
5. A written commitment by the institution to be "enabling" regarding hospital space (intensive care unit, odds ratios, wards) and staff (doctors, nurses, perfusionists, etc).

6. Statement of willingness to participate in a future cardiac surgical registry and database to help improve the gap in data available on cardiac surgery outside high-income countries.

The CSIA will be accepting applications through September 10,2019 , and all programs are encouraged to apply. If not selected for the initial pilot site, all applications will be entered into a database for consideration at a future date.
Applications and supporting documents should be submitted to:

World Heart Federation

CSIA Proposals

32 rue de Malatrex

1201 Geneva

Switzerland

E-mail: kate.ralston@worldheart.org

If you have any queries, please contact Chip Bollman at cbolman46@gmail.com; for more information on CSIA, visit www.CSIAforRHD.org

\section{THE PILLARS OF CSIA SUPPORTED PROJECTS}

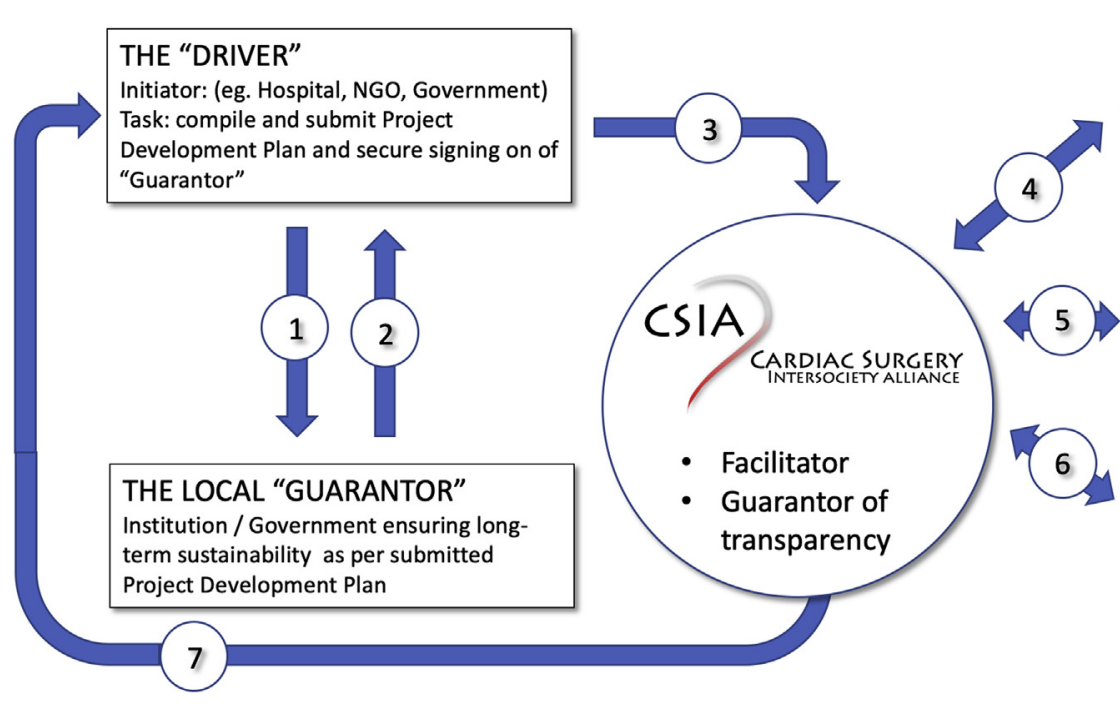

THE "SPONSOR"

Industry Partner / NGO taking on the patronage over 2 aspects:

(1) Enabling local capacity (increase) (eg through donating consumables)

(2) Enabling capacity increase for training at "Training Site" (eg through donation of consumables).

THE "TRAINING SITE"

Middle-Income-Country (MIC) - based covering full CS spectrum incl. CHD $(>500$ cases/year)

THE "ACADEMIC PARTNER"

Renowned High-Income-Country (HIC) Institution taking bon the patronage of the site specific research 